\title{
Lymphatics-associated genes are downregulated at transcription level in non-small cell lung cancer
}

\author{
OKSANA KOWALCZUK ${ }^{1}$, JERZY LAUDANSKI ${ }^{2}$, WOJCIECH LAUDANSKI ${ }^{2}$, \\ WIESLAWA EWA NIKLINSKA ${ }^{3}$, MIROSLAW KOZLOWSKI ${ }^{2}$ and JACEK NIKLINSKI $^{1}$ \\ Departments of ${ }^{1}$ Clinical Molecular Biology, ${ }^{2}$ Thoracic Surgery and ${ }^{3}$ Histology and \\ Embryology, Medical University of Bialystok, 15-269 Bialystok, Poland
}

Received March 18, 2017; Accepted October 17, 2017

DOI: $10.3892 / \mathrm{ol} .2018 .8159$

\begin{abstract}
The present study aimed to verify a possibility of ongoing lymphangiogenesis in non-small cell lung cancer (NSCLC) via examination of mRNA levels of a number of lymphangiogenesis-associated genes in tumors. It was hypothesized that transcriptional activation of these genes would occur in tumors that stimulate new lymphatic vessel formation. The study was performed on 140 pairs of fresh-frozen surgical specimens of cancer and unaffected lung tissues derived from NSCLC stage I-IIIA patients. mRNA levels were evaluated with the reverse transcription-quantitative polymerase chain reaction method and expressed as fold change differences between the tumor and normal tissues. Possible associations between expression and patient clinicopathological characteristics and survival were analyzed. In the NSCLC tissue samples, vascular endothelial growth factor (VEGF) C, VEGFD, VEGFR3, VEGFR2, VEGFR1, lymphatic vessel endothelial hyaluronan receptor 1, integrin subunit $\alpha 9$, FOX2, neuropilin 2, fibroblast growth factor 2 genes were significantly downregulated $(\mathrm{P}<0.001$ for all) compared with matched normal lung tissues, whereas mRNA levels for VEGFA, spleen associated tyrosine kinase, podoplanin, and prospero homeobox 1 genes were similar in both tissues. Neither lymph node status, nor disease pathological stage influenced expression, whereas more profound suppression of gene activities appeared to occur in squamous cell carcinomas compared with adenocarcinomas. The VEGFR1 mRNA expression level was significantly connected with patient survival in the univariate analysis, and was an independent prognostic factor for overall survival in the multivariate Cox's proportional hazards model (HR 2.103; 95\% confidence interval: 1.005-4.401; $\mathrm{P}=0.049$ ). The results support a hypothesis of absence of new lymphatic
\end{abstract}

Correspondence to: Professor Jacek Niklinski, Department of Clinical Molecular Biology, Medical University of Bialystok, 13 Waszyngtona, 15-269 Bialystok, Poland

E-mail: jacek.niklinski@umb.edu.pl

Key words: non-small cell lung cancer, lymphangiogenesis, gene expression, NSCLC, VEGFR1, PROX1, PDPN vessel formation inside growing NSCLC tumor mass, however do not exclude a possibility of lymphangiogenesis in narrow marginal tumor parts.

\section{Introduction}

The lymphatic system forms an extensive network of low shear force vessels that penetrates almost all organs of the human body. It plays a key role in the maintenance of tissue-fluid homeostasis and is essential for the immune system functioning (1). Lymphatic vasculature has long been considered one of the main routes of solid tumors metastatic dissemination to distant organs $(2,3)$. Highly-permeable and comparatively wide lymphatic capillaries seem to be well accommodated to tumor cell transport from the primary tumor mass into the blood circulation. Sentinel lymph nodes that directly drain primary tumors are usually the first sites of detectable metastases. Histological examination of these and nearby lymph nodes is routinely used for determining the stage of disease progression and for prediction of patients' survival (4). Moreover, it has become clear that lymphatics profoundly affects cancer progression (5). Growing evidence indicates that direct modulation of immune cell functions by lymphatic endothelial cells (LECs) may be essential for both antitumor immune response at early stages of tumor progression and subsequent cancer-induced immunosuppression (6). Based on these assumptions, it has been proposed that tumors may stimulate formation of new lymphatic vessel via process of lymphangiogenesis in a manner analogous to tumor angiogenesis, thereby promoting both tumorigenesis and lymphagenous metastasis $(3,5,7)$.

Evidence for ongoing lymphangiogenesis inside growing tumors was initially provided from animal studies. In experimental models of cancer, forced formation of intratumor lymphatic vasculature increased tumor aggressiveness and facilitated metastatic spread (8-11), while inhibition of the lymphangiogenesis prevented lymph node and distant metastases without significantly affecting primary tumor growth $(12,13)$. In agreement with these data, numerous clinical studies demonstrated an association between tumor expression of lymphatic-specific growth factors or lymph vessel density and tumor progression or poor patient survival (14-16). However, a lack of the correlation as well 
as an absence of proliferating LECs in the primary tumors were reported by others $(17,18)$. Moreover, detailed histological analyses of various solid tumors frequently failed to reveal lymphatic vessels throughout tumor masses except the periphery of these tumors (19-21), suggesting a lack of ongoing lymphangiogenesis. Besides, growing evidence suggests that lymphatics suppression might be favorable for tumor growth at early stages of cancer progression due to anti-tumor immune response weakening (22).

Thus, formation of new lymphatic vessels in growing human tumors remains an unresolved question. In order to evaluate a probability of lymphangiogenesis induction in non-small cell lung cancer (NSCLC), we performed a comprehensive analysis of the transcriptional activity of 15 genes encoding lymphatics regulators or markers (23-26). Using a comparative quantitative polymerase chain reaction (qPCR) method we examined the expression at mRNA level of the vascular endothelial growth factors: VEGFA, VEGFC, and VEGFD/FIFG, their receptors: VEGFR1/FLT1, FEGFR2/KDR, and VEGFR3/FLT4 and co-receptors neuropilin 2 (NRP2) and integrin a9 subunit (ITG9), basic fibroblast growth factor 2 (FGF2), transcription factors: prospero-related homeobox domain 1 (PROX1) and Forkhead box C2 (FOXC2), lymphatic-specific membrane proteins: lymphatic vessel hyaluronan receptor 1 (LYVE1) and glomerular podocyte mucoprotein podoplanin (PDPN), spleen protein kinase (SYK) and key component of desmosomal plaque proteins: desmoplakin (DSP). A brief characteristics of the analyzed factors is presented in Table I. Transcript levels were evaluated by comparison to those in non-malignant lung tissue and analyzed in terms of patients' clinicopathological characteristics.

\section{Materials and methods}

Patients and samples. The study was performed on 140 pairs of tumor and matched unaffected lung tissue specimens obtained from I-IIIA stage NSCLC patients who underwent a curative surgery at the Bialystok Medical University Hospital between 2000 and 2010. Disease staging was performed according to the seventh edition of the tumor-nodes-metastasis system (TNM) for lung cancer (27). None of the patients received chemo- or radiotherapy before the surgery. All of them gave the written informed consent for specimen collection and clinicopathological data processing. The study design was approved by the Ethics Committee of the University.

Tissue samples were collected intraoperatively and processed immediately after surgical removal according to the systematic biobanking quality (28). After the macroscopic visual assessment, the tumors were divided into two sections. One of them was fixed in formalin followed by paraffin embedding, and the other was divided into small pieces (approximately $0.5 \mathrm{~cm}$ in diameter) and frozen in liquid nitrogen followed by storage at $-80^{\circ} \mathrm{C}$. Unaffected lung parenchyma specimens were dissected from the same lobe or lung of the patient at an area at least $5 \mathrm{~cm}$ distant from the tumor and processed similarly to tumor specimens. Prior to RNA extraction, the cross-sections of frozen tissue samples were stained with hematoxylin-eozyn and evaluated by an experienced pathologist (L.C.) to confirm the suitability of cell content. Namely, tumor specimens with the highest percentage of the malignant cells (but at least
$60 \%$ of tumor cells on a microscopic section) and normal lung epithelium without metaplasia or dysplasia were used for further processing.

RNA extraction. Total RNA was isolated from tissue specimens by magnetic extraction method on EasyMag machine (bioMerieux, Marcy l'Étoile, France) according to the producer's protocol. The resulting RNA was transcripted into cDNA in a reaction with High Capacity RNA-to-cDNA Master Mix (Applied Biosystems; Thermo Fisher Scientific, Inc., Waltham, MA, USA) according to the producer's recommendations.

$m R N A$ expression level. For an mRNA level evaluation a TaqMan Low Density Array analysis was used: For each sample, amplification of all the analyzed transcripts was performed simultaneously in the MicroFluid Cards (Applied Biosystems; Thermo Fisher Scientific, Inc.) that contained manufactory loaded and dried commercially available primers/probe sets for gene expression examination (Assays-on-Demand; Applied Biosystems; Thermo Fisher Scientific, Inc.). Gene symbols and Assay-on-Demand accession numbers are summarized in Table I. Ribosomal $18 \mathrm{~S}$ RNA (18SrRNA) gene with a relatively low level of expression variability in lung cancer cell lines and clinical specimens (29) was used to normalize for the differences in the input cDNA concentration. Each channel of a card was loaded with $100 \mu \mathrm{l}$ of the reaction mixture containing $50 \mu 12 \mathrm{X}$ TaqMan Gene Expression Master Mix (Applied Biosystems; Thermo Fisher Scientific, Inc.) and $20 \mu \mathrm{l}$ of a cDNA solution (corresponding to $100 \mathrm{ng}$ of total RNA). The amplification was performed with ABI PRISM 7900HT Sequence Detection System equipped with the SDS v.2.4 software for baseline and $\mathrm{C}_{\mathrm{q}}$ calculations. The cycling conditions were as follows: $50^{\circ} \mathrm{C}$ for $2 \mathrm{~min}$ followed by $95^{\circ} \mathrm{C}$ for $10 \mathrm{~min}$ hold, 40 cycles of $95^{\circ} \mathrm{C}$ for $15 \mathrm{sec}$ and $60^{\circ} \mathrm{C}$ for $60 \mathrm{sec}$. Each sample was analyzed in triplicate. The raw $\mathrm{Cq}$ data for each mRNA $(\mathrm{Cq})$ was normalized as follows: $\Delta \mathrm{C}_{\mathrm{q}}=\mathrm{C}_{\mathrm{q}}-\mathrm{C}_{\mathrm{q} \text { ref }}$, where $\mathrm{C}_{\mathrm{q} \text { ref }}$ equaled the $\mathrm{C}_{\mathrm{t}}$ value of the reference $18 \mathrm{SrRNA}$ gene. Tumor-associated fold-changes (FC) in gene activities (relative expression) were calculated as follows: $\mathrm{FC}=2^{-\Delta \Delta \mathrm{Cq}}$, where $\Delta \Delta \mathrm{C}_{\mathrm{q}}$ equaled the differences between normalized expressions of the analyzed gene in tumor $\left(\Delta \mathrm{C}_{\mathrm{qT}}\right)$ and nonmalignant lung tissue $\left(\Delta \mathrm{C}_{\mathrm{qN}}\right)$ from the same patient $\left(\Delta \Delta \mathrm{C}_{\mathrm{q}}=\Delta \mathrm{C}_{\mathrm{qT}}-\Delta \mathrm{C}_{\mathrm{qN}}\right)$ (30). To examine possible associations between gene activity and patients' clinicopathological characteristics or survival, $\log _{2} \mathrm{FC}$ values were used. For survival analysis a median $\log _{2} \mathrm{FC}$ for each gene was used as a cutoff and the expression was categorized as high (equal or higher than the median) or low (lower than the median).

Statistical analysis. The differences in mRNA expression levels between the tumor and unaffected lung tissues were analyzed with paired Wilcoxon rank-sum test. The Wilcoxon rank-sum or Kruskal-Wallis rank tests were used to analyze the associations between clinicopathological characteristics and mRNA expression levels. OS was calculated and plotted with Kaplan-Meier method with the log-rank test for comparison between the groups. Cox proportional hazards method was used to evaluate the effect of clinicopathological and molecular variables on OS. $\mathrm{P}<0.05$ was considered to indicate a statistically significant difference. All the statistical 
Table I. Brief characteristics of the analysed genes.

\begin{tabular}{|c|c|c|c|}
\hline Gene symbol $^{\mathrm{a}}$ & $\begin{array}{l}\text { Brief characteristics of the encoded protein role in lymphatic } \\
\text { system development and functioning }\end{array}$ & Assay ID & (Refs.) \\
\hline$V E G F C$ & $\begin{array}{l}\text { Vascular endothelial growth factor C, a VEGF family member, is } \\
\text { the most potent inducer of lymphatic endothelial cell migration } \\
\text { and sprouting, is a ligand for the receptor tyrosine kinases } \\
\text { VEGFR2 and VEGFR3 }\end{array}$ & Hs01099203_m1 & $(5,25)$ \\
\hline VEGFD/FIGF & $\begin{array}{l}\text { Vascular endothelial growth factor D, a VEGF family member, is } \\
\text { an inducer of lymphatic sprouting }\end{array}$ & Hs01128657_m1 & $(5,25)$ \\
\hline$V E G F A$ & $\begin{array}{l}\text { Vascular endothelial growth factor A, a founder of VEGF family, } \\
\text { a key regulator of tumor angiogenesis, but also essential for } \\
\text { lymphatic vessel formation }\end{array}$ & Hs00900055_m1 & $(23,33)$ \\
\hline VEGFR3/FLT4 & $\begin{array}{l}\text { Vascular endothelial growth factor receptor 3, fms-like tyrosine } \\
\text { kinase } 4 \text {, the main receptor for VEGFC, also binds VEGFD, is } \\
\text { expressed by lymphatic endothelial cells, on some blood vessels } \\
\text { and stem cells }\end{array}$ & Hs01047677_m1 & $(5,25)$ \\
\hline VEGFR2/KDR & $\begin{array}{l}\text { Vascular endothelial growth factor receptor } 2 \text {, is found in blood } \\
\text { vessels and in a subset of lymphatic vessels, binds vascular } \\
\text { growth factors VEGFA and VEGFC }\end{array}$ & Hs00911700_m1 & $(23,33)$ \\
\hline VEGFR1/FLT1 & $\begin{array}{l}\text { Vascular endothelial growth factor receptor } 1 \text {, fms-like tyrosine } \\
\text { kinase } 1 \text {, VEGFA receptor }\end{array}$ & Hs01052961_m1 & $(23,33)$ \\
\hline$N R P 2$ & $\begin{array}{l}\text { Neuropilin-2-VEGFR3 co-receptor is found on lymphatic vessels, } \\
\text { binds the lymphangiogenic growth factors VEGFC and VEGFD, } \\
\text { also expressed on veins }\end{array}$ & Hs00187290_m1 & $(60,61)$ \\
\hline ITGA9 & $\begin{array}{l}\text { Integrin a9, cell-matrix adhesion receptor, is critical for lymphatic } \\
\text { valve maturation }\end{array}$ & Hs00979865_m1 & $(59)$ \\
\hline LYVE1 & $\begin{array}{l}\text { Lymphatic vessel hyaluronan receptor, is strongly expressed on the } \\
\text { surface of lymphatic endothelial cells of growing vessels during } \\
\text { lymphangiogenesis, and also on some blood vessels and } \\
\text { macrophages; participates in cell migration and differentiation }\end{array}$ & Hs00272659_m1 & $(35,36)$ \\
\hline$P D P N$ & $\begin{array}{l}\text { Podoplanin-glomerular podocyte mucoprotein, is expressed } \\
\text { on lymphatic but not on blood vessel endothelium, osteoblasts, } \\
\text { renal podocytes, lung alveolar cells; participates in cell motility }\end{array}$ & Hs00366766_m1 & $(38,54)$ \\
\hline PROXI & $\begin{array}{l}\text { Prospero-related homeobox domain } 1 \text { transcription factor, plays a } \\
\text { key role for lymphatic endothelial cell differentiation } \\
\text { and maintenance of their identity }\end{array}$ & Hs00896293_m1 & $(40,41)$ \\
\hline FOXC2 & $\begin{array}{l}\text { Forkhead box } \mathrm{C} 2 \text { transcription factor, is essential for the normal } \\
\text { development of the lymphatic system }\end{array}$ & Hs00270951_s1 & (37) \\
\hline$F G F 2$ & $\begin{array}{l}\text { Fibroblast growth factor } 2 \text {, is important for tumor angiogenesis } \\
\text { but also promotes lymphangiogenesis via an indirect mechanism } \\
\text { involving VEGFC/VEGFR3 signaling }\end{array}$ & Hs00266645_m1 & $(55)$ \\
\hline$S Y K$ & $\begin{array}{l}\text { Spleen tyrosine kinase, possible indirect role through inhibition } \\
\text { of cell motility and enhancement of cell-cell interactions }\end{array}$ & Hs00895377_m1 & $(58)$ \\
\hline$D S P$ & $\begin{array}{l}\text { Desmoplakin, a key component of desmosomal plague proteins, } \\
\text { may contribute to vessel formation }\end{array}$ & Hs00950591_m1 & $(56,57)$ \\
\hline
\end{tabular}

${ }^{\text {a} A c c o r d i n g ~ t o ~ H U G O ~ G e n e ~ N o m e n c l a t u r e ~ C o m m i t t e e . ~}$

analyses in this study were performed using STATA/SE 11.1 software (Stata Corporation, College Station, TX, USA.

\section{Results}

Patient characteristics. A total of 140 NSCLC patients, aged from 39 to 79 years (mean 62, standard deviation 8.0 years), were included in the study. The majority of the patients (117 out of $140,84 \%$ ) were males. Among the patients, 57 (41.4\%) had lung adenocarcinoma (ADC), 66 (47.1\%) had squamous cell carcinoma (SCC), and the remaining 17 (11.4\%) had large cell lung carcinoma (LCC). Forty-five tumors were recognized as highly differentiated (grade 1 or 2), and fifty-five were lowly differentiated ones (grade 3 or 4). Lymph node metastasis was 
Table II. Gene expression at mRNA level in tumor and non-tumor lung tissue $\left[\log _{2}(\Delta \mathrm{Cq})\right]$ and the difference in the log-FC between the paired tissues $\left[\log _{2}(\mathrm{FC})\right]$.

mRNA level $\left[\log _{2}(\Delta \mathrm{Cq})\right]$

\begin{tabular}{|c|c|c|c|c|c|}
\hline \multirow[b]{2}{*}{ Gene symbol } & \multirow[b]{2}{*}{$\mathrm{N}$} & & \multirow[b]{2}{*}{ P-value } & \multirow{2}{*}{$\begin{array}{c}\text { lung tissues }\left[\log _{2}(\mathrm{FC})\right] \\
\mathrm{Me}(25-75 \%)\end{array}$} \\
\hline & & Tumor tissue Me (25-75\%) & Normal lung tissue $\mathrm{Me}(25-75 \%)$ & & \\
\hline$V E G F C$ & 136 & $17.67(16.33-18.54)$ & $16.58(15.39-17.84)$ & $<0.0001$ & $-0.92(-1.88-0.06)$ \\
\hline$V E G F D$ & 136 & $18.75(16.37-21.74)$ & $15.57(14.27-16.55)$ & $<0.0001$ & $-2.72-(5.92-0.61)$ \\
\hline VEGFR3 & 136 & $18.72(17.65-19.53)$ & $17.39(16.79-18.27)$ & $<0.0001$ & $-0.89-(1.95-0.16)$ \\
\hline LYVE1 & 136 & $18.91(17.15-20.23)$ & $16.69(15.31-17.68)$ & $<0.0001$ & $-2.08-(3.37-0.48)$ \\
\hline ITGA9 & 136 & $16.06(15.16-17.34)$ & $15.43(14.45-16.22)$ & $<0.0001$ & $-1.02(-1.86-0.14)$ \\
\hline$P D P N$ & 136 & $15.71(14.45-16.96)$ & $15.75(14.50-16.81)$ & 0.640 & $-0.13(-1.15-1.30)$ \\
\hline$D S P$ & 137 & $13.81(11.93-15.59)$ & $16.66(15.12-17.52)$ & $<0.0001$ & $2.58(0.44-4.39)$ \\
\hline PROXI & 136 & $20.53(18.27-21.80)$ & $20.47(18.95-22.09)$ & 0.611 & $0.17(-1.21-1.70)$ \\
\hline FOXC1 & 136 & $15.27(14.04-16.44)$ & $13.96(13.06-15.03)$ & 0.0003 & $-1.45(-2.29-0.41)$ \\
\hline$N R P 2$ & 136 & $14.16(12.78-15.29)$ & $13.97(12.61-14.99)$ & 0.021 & $-0.16(-1.12-0.55)$ \\
\hline$V E G F A$ & 136 & $13.34(11.86-14.77)$ & $13.37(11.97-14.76)$ & 0.861 & $0.03(-0.81-0.80)$ \\
\hline$F G F 2$ & 137 & $19.57(17.46-20.50)$ & $18.05(16.86-19.05)$ & 0.0002 & $-1.10(-2.41-0.24)$ \\
\hline VEGFRI & 136 & $16.99(15.48-18.40)$ & $16.83(14.73-17.42)$ & 0.0002 & $-0.92-(1.78-0.15)$ \\
\hline VEGFR2 & 136 & $16.13(14.65-17.85)$ & $15.11(13.63-16.56)$ & $<0.0001$ & $-1.16(-2.18-0.10)$ \\
\hline SYK & 138 & $16.27(15.28-17.40)$ & $16.16(15.02-17.50)$ & 0.387 & $-0.30(-1.11-1.61)$ \\
\hline
\end{tabular}

FC, fold-change; VEGF, vascular endothelial growth factor; LYVE1, lymphatic vessel hyaluronan receptor 1; ITGA9, integrin a9; PDPN, podoplanin; DSP, desmoplakin; PROX1, prospero-related homeobox domain 1; FOXC1, Forkhead box C1; NRP2, neuropilin 2; FGF2, fibroblast growth factor 2; SYK, spleen protein kinase.

detected in $60(42.9 \%)$ patients. Fifty-seven (40.8\%) patients had TNM stage I disease, $66(47.1 \%)$ had stage II disease, and 17 patients $(12.1 \%)$ had stage III disease.

Differential gene expression between tumor and non-tumor lung tissues. Ten out of 15 analyzed genes (VEGFC, VEGFD, VEGFR3, VEGFR1, VEGFR2, FGF2, SYK, LYVE1, ITGA, and $F O X C 2)$ showed a significantly lower mRNA level in tumors compared with non-tumor tissues. Four genes (PROX1, $P D P N, N R P 2$, and VEGFA) had similar expression levels in the tumors and in the normal samples, and only for one gene $(D S P)$ an increase in expression in tumors was observed (Table II).

Associations between transcript level and clinicopathological characteristics. The analysis of the effect of patients' clinicopathological features on gene expression revealed a relatively limited and differentiated influence on the fold-change values. In particular, tumor-associated downregulation of the expression for VEGFC $(\mathrm{P}=0.049)$, VEGFR3 $(\mathrm{P}=0.107)$, VEGFR2 $(\mathrm{P}=0.028)$, and ITGA $(\mathrm{P}=0.011)$ genes was higher in SCC than in ADC or LCC, and two genes (PROX1 and VEGFA) were downregulated in SCC but not in non-squamous histological types $(\mathrm{P}=0.005$ and $\mathrm{P}=0.012$ for $P R O X 1$ and $V E G F A$, respectively) (Fig. 1A-F). In larger tumors, suppression of VEGFR3 and $L Y V E 1$ activity was more significant than those in smaller ones $(\mathrm{P}=0.034$ and $\mathrm{P}=0.50$ for $V E G F R 3$ and $L Y V E 1$, respectively), whereas the opposite relation was revealed for $P D P N$ and $N R P 2$ genes $(\mathrm{P}=0.019$ and $\mathrm{P}=0.019$, respectively)
(Fig. 2A-D). However, we failed to find associations between the analyzed mRNA levels and lymph node metastases or disease stage. PDPN (P=0.049), SYK $(\mathrm{P}<0.001)$ and $F G F 2$ $(\mathrm{P}=0.041)$ transcriptional downregulation was more significant in high-graded tumors (G3 or G4) compared with low-graded ones (G1 or G2) (Fig. 3A-C). Although unchanged in the whole cohort of our patients or in men, VEGFA expression was upregulated in tumors derived from women ( $\mathrm{P}=0.020)$ (Fig. 4A). In addition, more significant suppression of FGF2 $(\mathrm{P}=0.012)$, VEGFR2 $(\mathrm{P}=0.045)$, and ITGA $(\mathrm{P}=0.005)$ transcription was observed in men compared to women (Fig. 4B-D).

The effects of gene expression level on patients' survival. The median follow-up time was equal to 54.6 months (ranged from 2 to 86 months). During the follow-up, 64 (45.6\%) patients had disease recurrence and all of them had died. In the Kaplan-Meier curve analysis, none of the analyzed parameters influenced OS, except VEGFRI expression. The OS rate of the patients with low VEGFRl expression was significantly shorter than that of the patients with high expression level $(\mathrm{P}=0.045)$. In multivariate analysis by Cox's proportional hazards method, low VEGFR 1 expression was an independent prognostic factor for a poor OS time (HR 2.103; 95\% CI: 1.005-4.401; $\mathrm{P}=0.049$ ) (Table III).

\section{Discussion}

NSCLC remains one of the most life-threatening human malignances (31), mostly due to early metastasis 
A

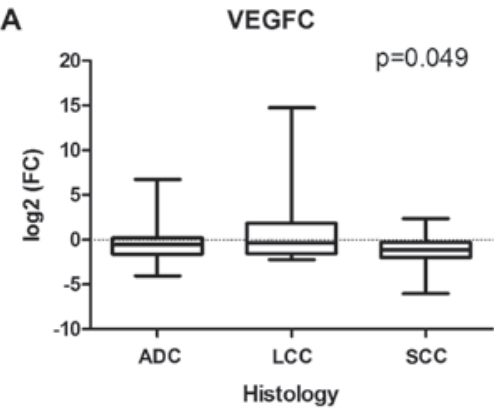

C

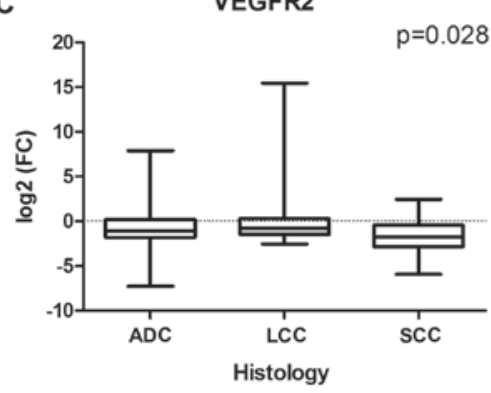

E

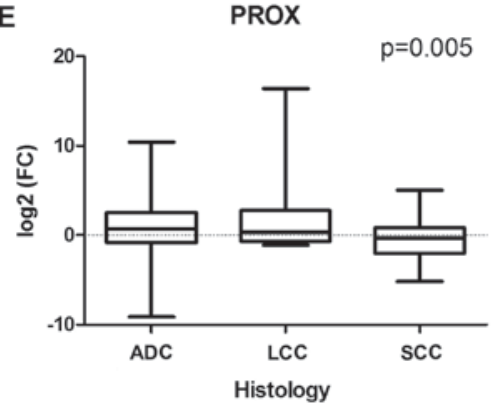

B

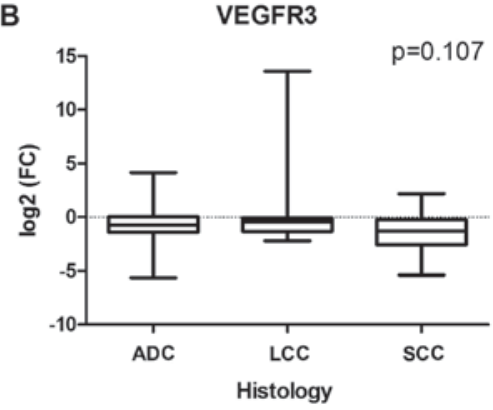

D

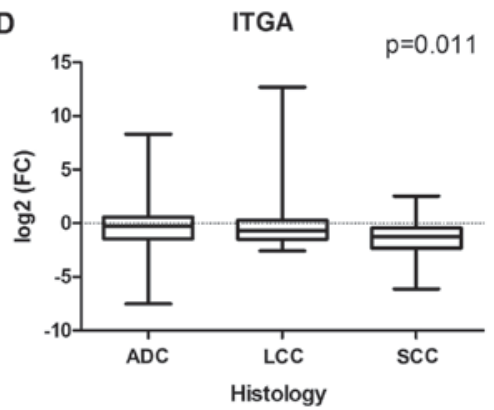

$\mathbf{F}$

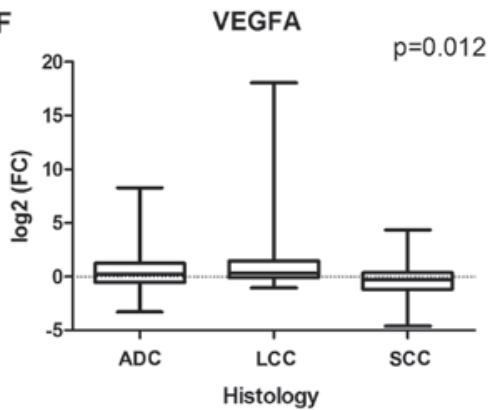

Figure 1. Associations between NSCLC histological type and (A) VEGFC, (B) VEGFR3, (C) VEGFR2, (D) ITGA, (E) PROX1 and (F) VEGFA mRNA expression level, defined as $\log _{2}(\mathrm{FC})$. NSCLC, non-small cell lung cancer; VEGF, vascular endothelial growth factor; ITGA9, integrin a9; PROX1, prospero-related homeobox domain 1; ADC, adenocarcinoma; LCC, large cell carcinoma; SCC, squamous cell carcinoma; FC, fold-change difference in mRNA level.

occurrence (32). Although lymphatic system has long been considered one of the main routes of cancer cell dissemination to distant organs $(2,3)$, an issue of new lymphatic vessel formation in solid tumors, including lung cancer, remains unresolved (33). The aim of the present study was to examine a possible impact of lung cancer cells on lymphangiogenesis induction within lung tumor mass. To do that we, firstly, analyzed mRNA expression level of well-established lymphangiogenesis inductors and markers (namely, VEGFC, VEGFD, VEGFR3, LYVE1, PDPN) and also of a number of pleiotrophic factors with reported contribution to the process (VEGFA, FGF2, NRP2, PROX1 and others). Secondly, although we did not perform tissue microdissection to exclude the influence of nonmalignant stromal cells on the analyzed parameters, we used lung cancer tissue specimens enriched in malignant cells (a median cancer cell content was $80 \%$, ranged from 60 to $100 \%$ ). Thirdly, we compared the expression level of the examined genes in tumors with that in the nonmalignant lung tissue derived from the same patient. We assumed that transcriptional activation (an increase in transcript level in tumors compared with paired unaffected lung tissues) of the genes essential for lymphatic vessel formation, reorganization and maintenance had to be observed in lymphangiogenesis-inducing tumors.

Despite expectations, none of the analyzed genes, except $D S P$, was activated in tumor tissue. Moreover, in malignant tissues, a statistically significant decrease in transcript level was observed for growth factors VEGFC and VEGFD and their receptor VEGFR3 that are thought to be the most potent inductors of lymphatic vessel formation $(10,34,35)$, and transcripts for lymphatics-specific markers LYVE1 $(36,37)$ and FOXC2 (38). The expression levels of other well-estimated lymphatic molecules PDPN $(39,40)$ and PROX1 $(41,42)$ were similar to those in nonmalignant tissue. Moreover, neither lymph node status, nor disease stage influenced transcript level for these genes, while more significant suppression of gene activity seemed to occur in SCC, compared to ADC or LCC. Also, no impact of aforementioned genes on patients' survival was observed. Thus, our results do not confirm a hypothesis of lymphangiogenesis induction in NSCLC, but instead seem to indicate a possible transcriptional suppression of the process.

Similar results were recently published by Sanmartín et al (43), who analyzed the mRNA expression of all the VEGF family members, their receptors and co-receptors 
A

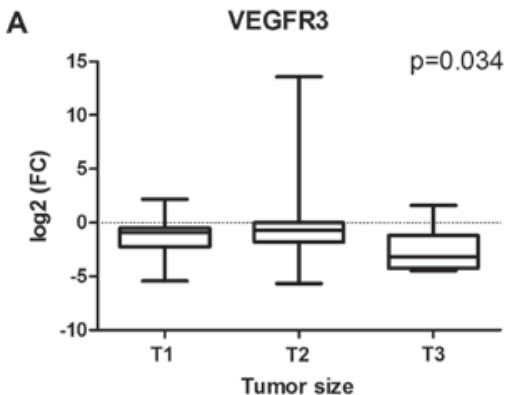

C

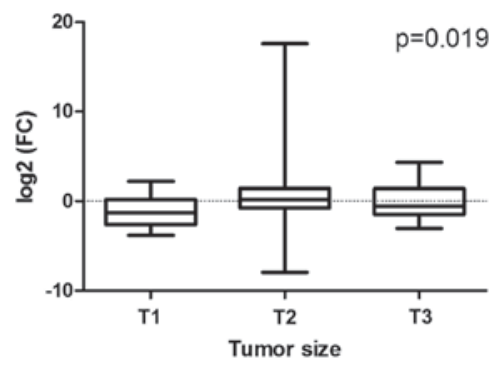

B

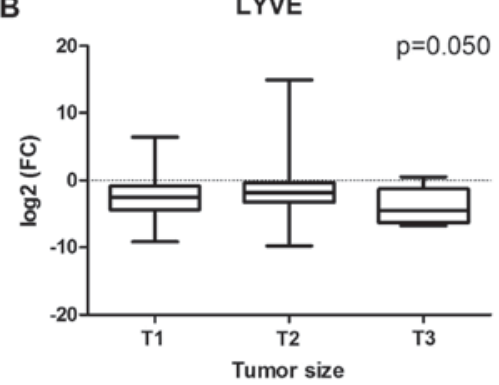

D

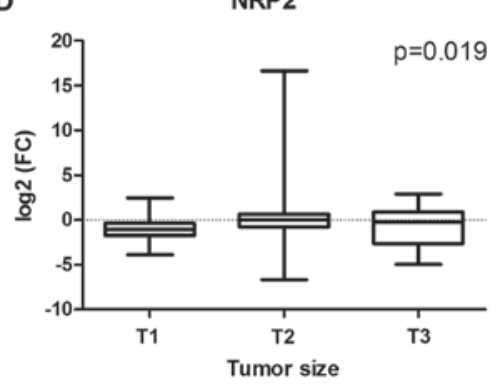

Figure 2. Associations between NSCLC tumor size and (A) VEGFR3, (B) LYVE1, (C) PDPN and (D) NRP2 mRNA expression level, defined as log 2 (FC) NSCLC, non-small cell lung cancer; VEGF, vascular endothelial growth factor; LYVE1, lymphatic vessel hyaluronan receptor 1; PDPN, podoplanin; NRP2, neuropilin 2; FC, fold-change, difference in mRNA level between tumor and normal lung tissues.

NRP1 and NRP2 in early-stage NSCLCs. The authors applied a similar methodological approach for mRNA evaluation and indicated significantly lower levels of VEGFD, VEGFR2, and $V E G F R 3$ mRNA in tumors, especially remarkable in the case of $V E G F D$ transcripts. Unfortunately, no information about the remaining analyzed genes has been reported by authors (43). Lower VEGFC and similar VEGFR3 mRNA expression levels in NSCLC tissues compared with normal lung tissues were also indicated by Takizawa et al (44). However, in another study, a differentiated $V E G F C$ and $V E G F D$ expression across tumor mass was indicated. In this analysis, a significantly reduced $V E G F C$ and $V E G F D$ mRNA expression was indicated in central tumor regions compared with the corresponding non-tumor lung tissues. However, in external tumor marginal regions, the mRNA level was found to be similar (for $V E G F C$ transcripts) or even higher (for $V E G F D$ transcripts) than those in non-tumoral tissues. Immunohistochemical examination confirmed these data. Moreover, the number of D2-40-immunostained lymphatic vessels was much higher at tumor periphery than in the central zone, and correlated with $V E G F C$ and VEGFD mRNA levels (45). These results suggest that formation of new lymphatic vessels in NSCLC may be restricted to the peripheral tumor zones. In the present study, we did not analyze separately internal and external tumor zones. Instead, specimens of bulk tumor mass enriched in malignant cells were used for transcript evaluation. In our opinion, our results do not confirm an induction of new lymphatic vessels formation in NSCLC.

We also failed to indicate associations between $V E G F C$, $V E G F D$ or $V E G F R 3$ mRNA expression and lymph node metastasis or patients' prognosis. Our data are partially consistent with previously reported observations, although in terms of the expression at mRNA level, limited and opposite data have also been reported. Thus, no associations between
VEGFC and VEGFR3 expression and lymph node status or patients' survival were indicated by Maekawa et al (46), whereas Takizawa et al (44) and Li et al (47) reported similar data for $V E G F C$ and VEGFR3 expression, respectively. In contrast, Takizawa et al (44) indicated significantly lower VEGFR3 mRNA levels in the node-positive group and an inverse relation in terms of VEGFC/VEGFR3 expression ratios. In respect to VEGFD, a negative correlation was found between VEGFD mRNA under-expression in NSCLC and lymph node metastasis $(43,46)$. In contrast, Feng et al $(45)$ indicated a positive correlation between VEGFC or VEGFD mRNA expression and lymph node metastases, but only in terms of the invasive marginal tumor regions.

Although studies on VEGFC, VEGFD, and VEGFR3 expression at mRNA level are limited, protein expression in NSCLC cells has been examined extensively by immunohistochemistry. A number of recent meta-analyses that summarize the results of these clinical investigations preferentially indicate positive VEGFC/D and VEGFR3 immunostaining in tumor cells and a positive correlation between the expression level and lymph node involvement or disease progression $(48,49)$. Similar data were obtained for breast, colorectal and esophageal cancer patients (50-52). However, in all the reports, significant discrepancies across particular studies have been highlighted. In our opinion, currently, there is no data to clearly support or oppose new lymphatic vessel formation in NSCLC.

In terms of the remaining genes examined in the present study, it is difficult to compare our results to previously reported data. Protein products of these genes have been demonstrated to be implicated in lymphatic system development, reorganization and maintenance in both physiological and pathological conditions $(24-26,34)$ and are widely used as markers for microscopic imaging of lymphatic vessels $(40,53)$. However, in addition to lymphatics, these protein are expressed in various 
A
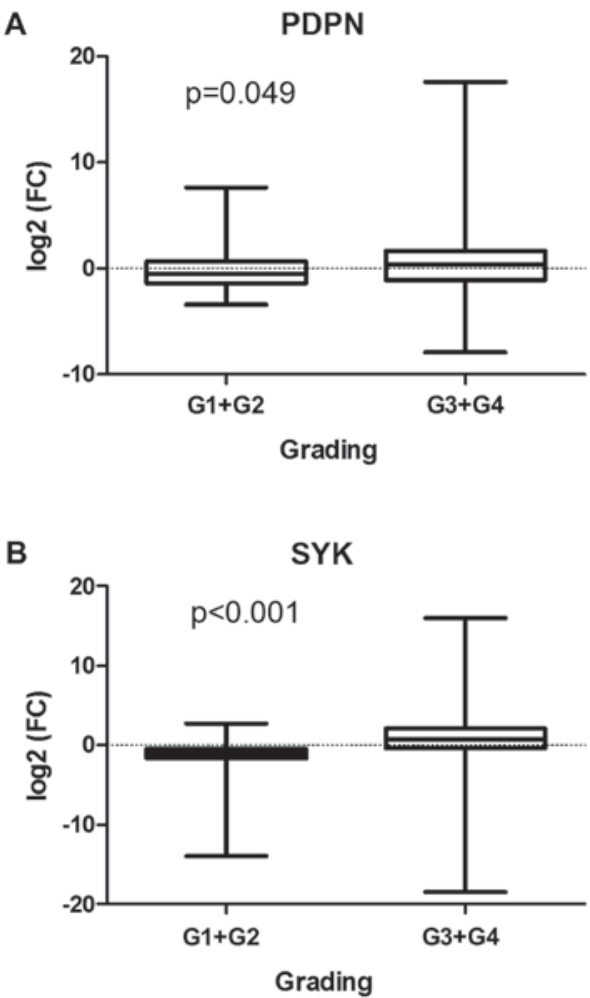

C

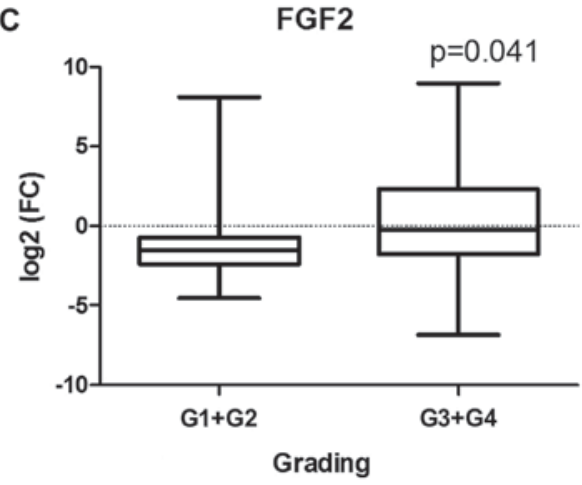

Figure 3. Associations between NSCLC grading and (A) PDPN, (B) SYK and (C) $F G F 2$ mRNA expression level, defined as $\log _{2}(\mathrm{FC})$. NSCLC, non-small cell lung cancer; PDPN, podoplanin; SYK, spleen protein kinase; FGF2, fibroblast growth factor 2 ; FC, fold-change, difference in mRNA level between tumor and normal lung tissues.

cell types and contribute to multiple molecular processes, including those in malignancies, as it has been demonstrated in a number of recent comprehensive reviews (54-62). This may provide an explanation for inconsistent data on the expression of analyzed proteins in cancer and their impact on tumor progression and clinical outcome (63-77).

For one of the genes, namely $D S P$, encoded for desmoplakin, an increase in mRNA level in NSCLC has been demonstrated. Desmoplakin is one of the main components of desmosomes that confer strong cell-cell adhesion and tissue resistance against mechanical stress but are also involved in cell proliferation, differentiation migration, morphogenesis and apoptosis $(57,58)$. A body of evidence indicates that desmosomal proteins are deregulated in various cancers and the deregulation contributes to cancerogenesis (58). Although a tumor-suppressive function of desmosomal proteins has mainly been postulated, discrepant data in the literature indicate that differential changes in their expression in tumor tissue may occur and possibly have different consequences (58).

Among the genes we examined here, there were those for growth factor VEGF and their receptors VEGFR1 and VEGFR2. VEGFA/VEGFR1-2 signaling is considered a key inductor of physiological and tumor-associated angiogenesis (78). Recently, VEGFA and VEGFR2 have also been implicated in tumor lymphangiogenesis $(3,5,33,34)$. Of interest, a number of clinical NSCLC studies demonstrated a positive correlation between high tumor cell VEGFA expression and lymph node metastasis $(79,80)$ and an inverse association in terms of stromal cell VEGFA expression (80). In our study, we failed to demonstrate VEGFAVEGFR1-2 signaling up-regulation in NSCLC, and these data seem to be discordant with a widely accepted view on angiogenesis induction in cancers (81). However, a gross of other factors have been found to stimulate new blood vessel formation, and tumors with VEGFA-independent angiogenesis $(82,83)$ or those co-opting preexisting vessels have been frequently indicated $(84,85)$.

In our study, VEGFRI mRNA expression level seemed to be linked to patients' survival $(\mathrm{P}=0,049)$. However, further investigations on larger patients cohort are needed to confirm this possibility. VEGFR1 is an alternative VEGFA receptor which also binds VEGFB and placental growth factor PIGF $(78,86)$. The prognostic value of this receptor expression in NSCLC remains controversial. In several recent studies, an unfavorable effect of high VEGFR1 expression on NSCLC patient' survival has been demonstrated $(87,49)$, whereas others found no correlation between the expression and the prognosis of the disease (88). To resolve discrepancies in the results further investigations are needed.

An important conclusion raising from our analysis reveals possible differences between NSCLC histological types in lymphangiogenesis regulation which are known to exist regarding new blood vessel formation and are taken into account in targeted antivascular therapy. We indicated a significantly lower VEGFC, VEGFR2, VEGFR3, and PROX1 mRNA expression in SCC compared with non-squamous NSCLC histological types, that suggests a more profound suppression of lymphangiogenesis in SCC and is in line with Takizawa et al data according to $V E G F C$ and $V E G F R 3$ mRNA levels (44).

In summary, our results demonstrate that the expression of the lymphangiogenesis-promoting factors in NSCLC cells seem to be suppressed at mRNA level early in cancer progression and more profoundly in SCC compared with ADC or LCC. These findings are in accordance with a recent hypothesis of absence of ongoing lymphangiogenesis inside a growing tumor mass, but do not exclude a possibility of lymphangiogenesis in narrow marginal tumor regions and a contribution of this lymphatics to lymph node metastasis. On the other hand, in the light of current knowledge on crosstalk between lymphatic and immune cells, our data may suggest a possibility of repression of active lymphatic function by tumor cells in order to reduce anti-tumor immunity. Of course, the some factors we had analyzed in the present study, are not limited only to lymphatic system development and functioning, but may play other multiple roles in both tumor and stromal cells, and alterations in their expression may depend on tumor biological characteristics and progression stage. 
Table III. Univariate and multivariable analysis of the prognostic effect of patients' clinicopathological characteristics and gene mRNA level [defined as $\log _{2}$ (fold-change) difference between NSCLC and non-tumor lung tissues] on overall survival (Cox proportional hazards model).

Univariate analysis Multivariate analysis

Variable Hazard ratio P-value 95\% confidence interval Hazard ratio P-value 95\% confidence interval

\begin{tabular}{|c|c|c|c|c|c|c|}
\hline Age & 1.448 & 0.138 & $0.888-2.361$ & & & \\
\hline Sex & 1.570 & 0.234 & $0.747-3.297$ & & & \\
\hline Histology & 0.979 & 0.873 & $0.759-1.263$ & & & \\
\hline Grading & 1.169 & 0.587 & $0.665-2.054$ & & & \\
\hline Tumor size & 1.749 & 0.036 & $1.037-2.948$ & 1.264 & 0.435 & $0.701-2.280$ \\
\hline Lymph node metastasis & 2.258 & 0.001 & $1.376-3.704$ & 0.836 & 0.642 & $0.392-1.780$ \\
\hline$T N M$ & 2.414 & $<0.001$ & $1.713-3.402$ & 2.542 & 0.001 & $1.486-4.346$ \\
\hline$V E G F C$ & 0.824 & 0.445 & $0.502-1.353$ & 0.557 & 0.259 & $0.201-1.539$ \\
\hline VEGFD/FIGF & 0.967 & 0.893 & $0.592-1.578$ & 1.480 & 0.481 & $0.498-4.401$ \\
\hline VEGFA & 1.322 & 0.275 & $0.800-2.184$ & 1.143 & 0.810 & $0.382-3.428$ \\
\hline VEGFR1/FLT1 & 2.110 & 0.046 & $1.012-4.392$ & 2.103 & 0.049 & $1.005-4.401$ \\
\hline$V E G F R 2 / K D R$ & 0.874 & 0.553 & $0.533-1.435$ & 0.805 & 0.684 & $0.284-2.285$ \\
\hline VEGFR3/FLT4 & 0.970 & 0.905 & $0.590-1.595$ & 1.179 & 0.761 & $0.409-3.411$ \\
\hline$N R P 2$ & 1.084 & 0.754 & $0.656-1.791$ & 1.156 & 0.800 & $0.376-3.553$ \\
\hline ITGA9 & 1.052 & 0.839 & $0.642-3.663$ & 0.924 & 0.868 & $0.364-2.347$ \\
\hline$F G F 2$ & 1.845 & 0.080 & $0.929-3.663$ & 2.161 & 0.094 & $0.878-5.334$ \\
\hline PROXI & 0.806 & 0.394 & $0.491-1.323$ & 0.829 & 0.686 & $0.335-2.052$ \\
\hline FOXC2 & 0.599 & 0.155 & $0.297-1.212$ & 0.569 & 0.222 & $0.230-1.406$ \\
\hline LYVE1 & 0.934 & 0.806 & $0.572-1.544$ & 1.277 & 0.663 & $0.425-3.837$ \\
\hline$P D P N$ & 1.156 & 0.569 & $0.703-1.901$ & 1.952 & 0.261 & $0.608-6.267$ \\
\hline$S Y K$ & 1.345 & 0.397 & $0.677-2.671$ & 1.297 & 0.605 & $0.843-3.481$ \\
\hline$D S P$ & 0.855 & 0.530 & $0.525-1.393$ & 0.458 & 0.068 & $0.197-1.060$ \\
\hline
\end{tabular}

NSCLC, non-small cell lung cancer; TNM, tumor-nodes-metastasis; VEGF, vascular endothelial growth factor; FLT, fms-like tyrosine; NRP2, neuropilin 2; ITGA9, integrin a9; FGF2, fibroblast growth factor 2; PROX1, prospero-related homeobox domain 1; FOXC2, Forkhead box C2; LYVE1, lymphatic vessel hyaluronan receptor 1; PDPN, podoplanin; SYK, spleen protein kinase; DSP, desmoplaki.
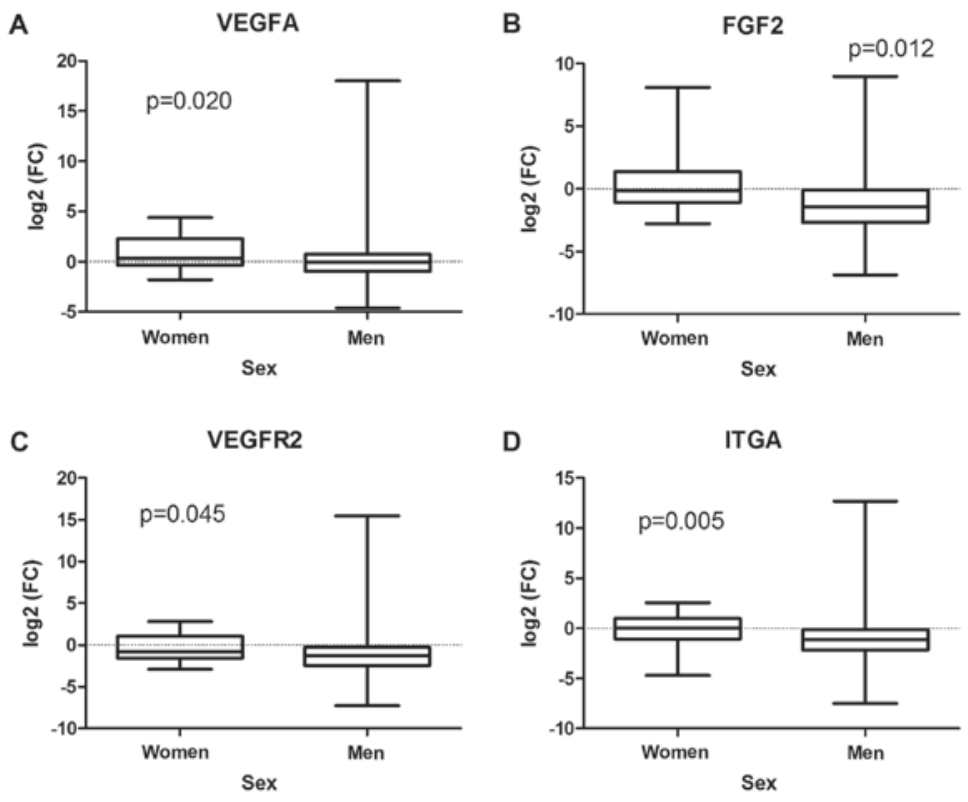

Figure 4. Associations between NSCLC patient sex and (A) VEGFA, (B) FGF2, (C) VEGFR2 and (D) ITGA mRNA expression level, defined as log 2 (FC) NSCLC, non-small cell lung cancer; VEGF, vascular endothelial growth factor; FGF2, fibroblast growth factor 2; ITGA, integrin a9; FC, fold-change, difference in mRNA level between tumor and normal lung tissues. 


\section{Acknowledgements}

This study was supported by the Polish Ministry of Science and Higher Education (funds for 2010-2014) grant no. N N 403577938 and conducted with the use of equipment purchased by Medical University of Bialystok as part of the OP DEP 2007-2013, Priority Axis I.3, contract no. POPW.01.03.00-20-022/09. The authors wish to thank Joanna Kisluk, $\mathrm{PhD}$ and Anna Michalska-Falkowska, $\mathrm{PhD}$ for editing and preparing the manuscript for publication.

\section{References}

1. Schulte-Merker S, Sabine A and Petrova TV: Lymphatic vascular morphogenesis in development, physiology, and disease. J Cell Biol 193: 607-618, 2011.

2. Alitalo K, Tammela T and Petrova TV: Lymphangiogenesis in development and human disease. Nature 438: 946-953, 2005.

3. Achen MG, McColl BK and Stacker SA: Focus on lymphangiogenesis in tumor metastasis. Cancer Cell 7: 121-127, 2005.

4. Edge SB and Compton CC: The American joint committee on cancer: The 7th edition of the AJCC cancer staging manual and the future of TNM. Ann Surg Oncol 17: 1471-1474, 2010.

5. Alitalo A and Detmar M: Interaction of tumor cells and lymphatic vessels in cancer progression. Oncogene 31: 4499-4508, 2012.

6. Stachura J, Wachowska M, Kilarski WW, Güç E, Golab J and Muchowicz A: The dual role of tumor lymphatic vessels in dissemination of metastases and immune response development. Oncoimmunology 5: e1182278, 2016.

7. Shields JD: Lymphatics: At the interface of immunity, tolerance, and tumor metastasis. Microcirculation 18: 517-531, 2011

8. MandriotaSJ,Jussila L, Jeltsch M,Compagni A, Baetens D, Prevo R, Banerji S, Huarte J, Montesano R, Jackson DG, et al: Vascular endothelial growth factor-C-mediated lymphangiogenesis promotes tumour metastasis. EMBO J 20: 672-682, 2001.

9. Skobe M, Hawighorst T, Jackson DG, Prevo R, Janes L, Velasco P, Riccardi L, Alitalo K, Claffey K and Detmar M: Induction of tumor lymphangiogenesis by VEGF-C promotes breast cancer metastasis. Nat Med 7: 192-198, 2001.

10. Stacker SA, Caesar C, Baldwin ME, Thornton GE, Williams RA, Prevo R, Jackson DG, Nishikawa S, Kubo H and Achen MG: VEGF-D promotes the metastatic spread of tumor cells via the lymphatics. Nat Med 7: 186-191, 2001.

11. Hoshida T, Isaka N, Hagendoorn J, di Tomaso E, Chen YL, Pytowski B, Fukumura D, Padera TP and Jain RK: Imaging steps of lymphatic metastasis reveals that vascular endothelial growth factor-C increases metastasis by increasing delivery of cancer cells to lymph nodes: Therapeutic implications. Cancer Res 66: 8065-8075, 2006.

12. He Y, Kozaki K, Karpanen T, Koshikawa K, Yla-Herttuala S, Takahashi T and Alitalo K: Suppression of tumor lymphangiogenesis and lymph node metastasis by blocking vascular endothelial growth factor receptor 3 signaling. J Natl Cancer Inst 94: 819-825, 2002.

13. Chen Z, Varney ML, Backora MW, Cowan K, Solheim JC, Talmadge JE and Singh RK: Down-regulation of vascular endothelial cell growth factor-C expression using small interfering RNA vectors in mammary tumors inhibits tumor lymphangiogenesis and spontaneous metastasis and enhances survival Cancer Res 65: 9004-9011, 2005.

14. Renyi-Vamos F, Tovari J, Fillinger J, Timar J, Paku S, Kenessey I, Ostoros G, Agocs L, Soltesz I and Dome B: Lymphangiogenesis correlates with lymph node metastasis, prognosis, and angiogenic phenotype in human non-small cell lung cancer. Clin Cancer Res 11: 7344-7353, 2005.

15. Miyahara M, Tanuma J, Sugihara K and Semba I: Tumor lymphangiogenesis correlates with lymph node metastasis and clinicopathologic parameters in oral squamous cell carcinoma. Cancer 110: 1287-1294, 2007.

16. Nakamura Y, Yasuoka H, Tsujimoto M, Imabun S, Nakahara M, Nakao K, Nakamura M, Mori I and Kakudo K: Lymph vessel density correlates with nodal status, VEGF-C expression, and prognosis in breast cancer. Breast Cancer Res Treat 91: 125-132, 2005 .
17. Agarwal B, Saxena R, Morimiya A, Mehrotra S and Badve S: Lymphangiogenesis does not occur in breast cancer. Am J Surg Pathol 29: 1449-1455, 2005.

18. Van der Schaft DW, Pauwels P, Hulsmans S, Zimmermann M, van de Poll-Franse LV and Griffioen AW: Absence of lymphangiogenesis in ductal breast cancer at the primary tumor site. Cancer Lett 254: 128-136, 2007.

19. Williams CS, Leek RD, Robson AM, Banerji S, Prevo R, Harris AL and Jackson DG: Absence of lymphangiogenesis and intratumoural lymph vessels in human metastatic breast cancer. J Pathol 200: 195-206, 2003.

20. Trojan L, Michel MS, Rensch F, Jackson DG, Alken P and Grobholz R: Lymph and blood vessel architecture in benign and malignant prostatic tissue: Lack of lymphangiogenesis in prostate carcinoma assessed with novel lymphatic marker lymphatic vessel endothelial hyaluronan receptor (LYVE-1). J Urol 172: 103-107, 2004.

21. Koukourakis MI, Giatromanolaki A, Sivridis E, Simopoulos C, Gatter KC, Harris AL and Jackson DG: LYVE-1 immunohistochemical assessment of lymphangiogenesis in endometrial and lung cancer. J Clin Pathol 58: 202-206, 2005.

22. Steinskog ES, Sagstad SJ, Wagner M, Karlsen TV, Yang N, Markhus CE, Yndestad S, Wiig H and Eikesdal HP: Impaired lymphatic function accelerates cancer growth. Oncotarget 7: 45789-45802, 2016.

23. Achen MG and Stacker SA: Molecular control of lymphatic metastasis. Ann N Y Acad Sci 1131: 225-234, 2008.

24. Hirakawa S: Regulation of pathological lymphangiogenesis requires factors distinct from those governing physiological lymphangiogenesis. J Dermatol Sci 61: 85-93, 2011.

25. Zheng W, Aspelund A and Alitalo K: Lymphangiogenic factors, mechanisms, and applications. J Clin Invest 124: 878-887, 2014.

26. Yoshimatsu Y, Miyazaki H and Watabe T: Roles of signaling and transcriptional networks in pathological lymphangiogenesis. Adv Drug Deliv Rev 99: 161-171, 2016.

27. Sobin LH and Compton CC: TNM seventh edition: What's new, what's changed: Communication from the international union against cancer and the American joint committee on cancer. Cancer 116: 5336-5339, 2010.

28. Niklinski J, Kretowski A, Moniuszko M, Reszec J, Michalska-Falkowska A, Niemira M, Ciborowski M, Charkiewicz R, Jurgilewicz D, Kozlowski M, et al: Systematic biobanking, novel imaging techniques, and advanced molecular analysis for precise tumor diagnosis and therapy: The Polish MOBIT project. Adv Med Sci 62: 405-413, 2017.

29. Endoh H, Tomida S, Yatabe Y, Konishi H, Osada H, Tajima K, Kuwano H, Takahashi T and Mitsudomi T: Prognostic model of pulmonary adenocarcinoma by expression profiling of eight genes as determined by quantitative real-time reverse transcriptase polymerase chain reaction. J Clin Oncol 22: 811-819, 2004.

30. Schmittgen TD and Livak KJ: Analyzing real-time PCR data by the comparative C(T) method. Nat Protoc 3: 1101-1118, 2008.

31. Torre LA, Siegel RL and Jemal A: Lung Cancer Statistics. Adv Exp Med Biol 893: 1-19, 2016.

32. Detterbeck FC, Postmus PE and Tanoue LT: The stage classification of lung cancer: Diagnosis and management of lung cancer, 3rd ed: American college of chest physicians evidence-based clinical practice guidelines. Chest 143 (5 Suppl): e191S-e210S, 2013.

33. Albrecht I and Christofori G: Molecular mechanisms of lymphangiogenesis in development and cancer. Int J Dev Biol 55: 483-494, 2011.

34. Gomes FG, Nedel F, Alves AM, Nör JE and Tarquinio SB: Tumor angiogenesis and lymphangiogenesis: Tumor/endothelial crosstalk and cellular/microenvironmental signaling mechanisms. Life Sci 92: 101-107, 2013.

35. Regan E, Sibley RC, Cenik BK, Silva A, Girard L, Minna JD and Dellinger MT: Identification of gene expression differences between lymphangiogenic and non-lymphangiogenic non-small cell lung cancer cell lines. PLoS One 11: e0150963, 2016.

36. Jackson DG: Biology of the lymphatic marker LYVE-1 and applications in research into lymphatic trafficking and lymphangiogenesis. APMIS 112: 526-538, 2004.

37. Wu M, Du Y, Liu Y, He Y, Yang C, Wang W and Gao F: Low molecular weight hyaluronan induces lymphangiogenesis through LYVE-1-mediated signaling pathways. PLoS One 9: e92857, 2014.

38. Wu X and Liu NF: FOXC2 transcription factor: A novel regulator of lymphangiogenesis. Lymphology 44: 35-41, 2011. 
39. Pan Y and Xia L: Emerging roles of podoplanin in vascular development and homeostasis. Front Med 9: 421-430, 2015.

40. Baluk P and McDonald DM: Markers for microscopic imaging of lymphangiogenesis and angiogenesis. Ann N Y Acad Sci 1131: $1-12,2008$

41. Elsir T, Smits A, Lindström MS and Nistér M: Transcription factor PROX1: Its role in development and cancer. Cancer Metastasis Rev 31: 793-805, 2012.

42. Watabe T: Roles of transcriptional network during the formation of lymphatic vessels. J Biochem 152: 213-220, 2012

43. Sanmartín E, Sirera R, Usó M, Blasco A, Gallach S, Figueroa S, Martínez N, Hernando C, Honguero A, Martorell M, et al: A gene signature combining the tissue expression of three angiogenic factors is a prognostic marker in early-stage non-small cell lung cancer. Ann Surg Oncol 21: 612-620, 2014.

44. Takizawa H, Kondo K, Fujino H, Kenzaki K, Miyoshi T, Sakiyama S and Tangoku A: The balance of VEGF-C and VEGFR-3 mRNA is a predictor of lymph node metastasis in non-small cell lung cancer. Br J Cancer 95: 75-79, 2006

45. Feng Y, Wang W, Hu J, Ma J, Zhang Y and Zhang J: Expression of VEGF-C and VEGF-D as significant markers for assessment of lymphangiogenesis and lymph node metastasis in non-smal cell lung cancer. Anat Rec (Hoboken) 293: 802-812, 2010.

46. Maekawa S, Iwasaki A, Shirakusa T, Enatsu S, Kawakami T, Kuroki M and Kuroki M: Correlation between lymph node metastasis and the expression of VEGF-C, VEGF-D and VEGFR-3 in T1 lung adenocarcinoma. Anticancer Res 27: 3735-3741, 2007.

47. Li J, Yi H, Liu Z, Zhang H, Zhang D, Yue W, Jia H, Xu S and Li B: Association between VEGFR-3 expression and lymph node metastasis in non-small-cell lung cancer. Exp Ther Med 9: 389-394, 2015

48. Kilvaer TK, Paulsen EE, Hald SM, Wilsgaard T, Bremnes RM, Busund LT and Donnem T: Lymphangiogenic markers and their impact on nodal metastasis and survival in non-small cell lung cancer-a structured review with meta analysis. PLoS One 10: e0132481, 2015

49. Zheng CL, Qiu C, Shen MX, Qu X, Zhang TH, Zhang JH and Du JJ: Prognostic impact of elevation of vascular endothelial growth factor family expression in patients with non-small cell lung cancer: An updated meta-analysis. Asian Pac J Cancer Prev 16: 1881-1895, 2015.

50. Zhang Z, Luo G, Tang H, Cheng $\mathrm{C}$ and Wang P: Prognostic significance of high VEGF-C expression for patients with breast cancer: An update meta analysis. PLoS One 11: e0165725, 2016

51. Zong S, Li H, Shi Q, Liu S, Li W and Hou F: Prognostic significance of VEGF-C immunohistochemical expression in colorecta cancer: A meta-analysis. Clin Chim Acta 458: 106-114, 2016.

52. Xia H, Shen J, Chen S, Huang H, Xu Y and Ma H: Overexpression of VEGF-C correlates with a poor prognosis in esophageal cancer patients. Cancer Biomark 17: 165-170, 2016.

53. Kato S, Shimoda H, Ji RC and Miura M: Lymphangiogenesis and expression of specific molecules as lymphatic endothelial cell markers. Anat Sci Int 81: 71-83, 2006.

54. Jackson DG: Immunological functions of hyaluronan and its receptors in the lymphatics. Immunol Rev 230: 216-231, 2009.

55. Ugorski M, Dziegiel P and Suchanski J: Podoplanin-a small glycoprotein with many faces. Am J Cancer Res 6 : 370-386, 2016

56. Akl MR, Nagpal P, Ayoub NM, Tai B, Prabhu SA, Capac CM Gliksman M, Goy A and Suh KS: Molecular and clinical significance of fibroblast growth factor 2 (FGF2/bFGF) in malignancies of solid and hematological cancers for personalized therapies. Oncotarget 7: 44735-44762, 2016

57. Kowalczyk AP and Green KJ: Structure, function, and regulation of desmosomes. Prog Mol Biol Transl Sci 116: 95-183, 2013.

58. Huber $\mathrm{O}$ and Petersen I: 150th anniversary series: Desmosomes and the hallmarks of cancer. Cell Commun Adhes 22: 15-28, 2015.

59. Krisenko MO and Geahlen RL: Calling in SYK: SYK's dual role as a tumor promoter and tumor suppressor in cancer. Biochim Biophys Acta 1853: 254-263, 2015.

60. Bazigou E, Xie S, Chen C, Weston A, Miura N, Sorokin L, Adams R, Muro AF, Sheppard D and Makinen T: Integrin-alpha9 is required for fibronectin matrix assembly during lymphatic valve morphogenesis. Dev Cell 17: 175-186, 2009.

61. Rizzolio S and Tamagnone L: Multifaceted role of neuropilins in cancer. Curr Med Chem 18: 3563-3575, 2011.

62. Zachary I: Neuropilins: Role in signalling, angiogenesis and disease. Chem Immunol Allergy 99: 37-70, 2014
63. Sasahira T, Ueda N, Yamamoto K, Kurihara M, Matsushima S, Bhawal UK, Kirita T and Kuniyasu H: Prox1 and FOXC2 act as regulators of lymphangiogenesis and angiogenesis in oral squamous cell carcinoma. PLoS One 9: e92534, 2014

64. Prud'homme GJ and Glinka Y: Neuropilins are multifunctional coreceptors involved in tumor initiation, growth, metastasis and immunity. Oncotarget 3: 921-939, 2012

65. Jiang W, Fan H, Qian C, Ding J, Wang Q and Pang X: Prognostic value of high FoxC2 expression in resectable non-small cell lung cancer, alone or in combination with E-cadherin expression. BMC Cancer 16: 16, 2016.

66. Zhu JL, Song YX, Wang ZN, Gao P, Wang MX, Dong YL, Xing $\mathrm{CZ}$ and $\mathrm{Xu} \mathrm{HM}$ : The clinical significance of mesenchyme forkhead 1 (FoxC2) in gastric carcinoma. Histopathology 62: 1038-1048, 2013

67. Nishida N, Mimori K, Yokobori T, Sudo T, Tanaka F, Shibata K, Ishii H, Doki Y and Mori M: FOXC2 is a novel prognostic factor in human esophageal squamous cell carcinoma. Ann Surg Oncol 18: 535-542, 2011.

68. Skog M, Bono P, Lundin M, Lundin J, Louhimo J, Linder N, Petrova TV, Andersson LC, Joensuu H, Alitalo K and Haglund $\mathrm{CH}$ : Expression and prognostic value of transcription factor PROX1 in colorectal cancer. Br J Cancer 105: 1346-1351, 2011.

69. Versmold B, Felsberg J, Mikeska T, Ehrentraut D, Köhler J, Hampl JA, Röhn G, Niederacher D, Betz B, Hellmich M, et al: Epigenetic silencing of the candidate tumor suppressor gene PROX1 in sporadic breast cancer. Int J Cancer 121: 547-554, 2007.

70. Schneider M, Büchler P, Giese N, Giese T, Wilting J, Büchler MW and Friess $\mathrm{H}$ : Role of lymphangiogenesis and lymphangiogenic factors during pancreatic cancer progression and lymphatic spread. Int J Oncol 28: 883-890, 2006.

71. Juchniewicz A, Niklińska W, Kowalczuk O, Laudański W, Sulewska A, Dziegielewski P, Milewski R, Naumnik W, Kozłowski M and Nikliński J: Prognostic value of vascular endothelial growth factor-C and podoplanin mRNA expression in esophageal cancer. Oncol Lett 10: 3668-3674, 2015.

72. Kadota K, Huang CL, Liu D, Nakashima N, Yokomise H, Ueno $\mathrm{M}$ and Haba R: The clinical significance of the tumor cell D2-40 immunoreactivity in non-small cell lung cancer. Lung Cancer 70: 88-93, 2010.

73. Shimada Y, Ishii G, Nagai K, Atsumi N, Fujii S, Yamada A, Yamane Y, Hishida T, Nishimura M, Yoshida J, et al: Expression of podoplanin, CD44, and p63 in squamous cell carcinoma of the lung. Cancer Sci 100: 2054-2059, 2009.

74. Ito T, Ishii G, Nagai K, Nagano T, Kojika M, Murata Y, Atsumi N, Nishiwaki Y, Miyazaki E, Kumamoto T and Ochiai A: Low podoplanin expression of tumor cells predicts poor prognosis in pathological stage IB squamous cell carcinoma of the lung, tissue microarray analysis of 136 patients using 24 antibodies. Lung Cancer 63: 418-424, 2009.

75. Ikoma Y, Kijima H, Masuda R, Tanaka M, Inokuchi S and Iwazaki M: Podoplanin expression is correlated with the prognosis of lung squamous cell carcinoma. Biomed Res 36: 393-402, 2015.

76. Suzuki H, Onimaru M, Yonemitsu Y, Maehara Y, Nakamura S and Sueishi K: Podoplanin in cancer cells is experimentally able to attenuate prolymphangiogenic and lymphogenous metastatic potentials of lung squamoid cancer cells. Mol Cancer 9: 287, 2010.

77. Kawakami T, Tokunaga $\mathrm{T}$, Hatanaka H, Kijima $\mathrm{H}$, Yamazaki $\mathrm{H}$, Abe $\mathrm{Y}$, Osamura $\mathrm{Y}$, Inoue $\mathrm{H}$, Ueyama $\mathrm{Y}$ and Nakamura M: Neuropilin 1 and neuropilin 2 co-expression is significantly correlated with increased vascularity and poor prognosis in nonsmall cell lung carcinoma. Cancer 95: 2196-2201, 2002.

78. Hicklin DJ and Ellis LM: Role of the vascular endothelial growth factor pathway in tumor growth and angiogenesis. J Clin Oncol 23: 1011-1027, 2005.

79. Donnem T, Al-Saad S, Al-Shibli K, Delghandi MP, Persson M, Nilsen MN, Busund LT and Bremnes RM: Inverse prognostic impact of angiogenic marker expression in tumor cells versus stromal cells in non small cell lung cancer. Clin Cancer Res 13: 6649-6657, 2007.

80. Donnem T, Al-Shibli K, Al-Saad S, Delghandi MP, Busund LT and Bremnes RM: VEGF-A and VEGFR-3 correlate with nodal status in operable non-small cell lung cancer: Inverse correlation between expression in tumor and stromal cells. Lung Cancer 63: $277-283,2009$ 
81. Shahneh FZ, Baradaran B, Zamani F and Aghebati-Maleki L: Tumor angiogenesis and anti-angiogenic therapies. Hum Antibodies 22: 15-19, 2013

82. Ferrara N: Role of myeloid cells in vascular endothelial growth factor-independent tumor angiogenesis. Curr Opin Hematol 17: 219-224, 2010

83. Zhao Y and Adjei A: Targeting angiogenesis in cancer therapy: Moving beyond vascular endothelial growth factor Oncologist 20: 660-673, 2015.

84. Donnem T, Hu J, Ferguson M, Adighibe O, Snell C, Harris AL, Gatter KC and Pezzella F: Vessel co-option in primary human tumors and metastases: An obstacle to effective anti-angiogenic treatment? Cancer Med 2: 427-436, 2013.

85. Bridgeman VL, Vermeulen PB, Foo S, Bilecz A, Daley F, Kostaras E, Nathan MR, Wan E, Frentzas S, Schweiger T, et al: Vessel co-option is common in human lung metastases and mediates resistance to anti-angiogenic therapy in preclinical lung metastasis models. J Pathol 241: 362-374, 2017.
86. Vieira JM, Ruhrberg C and Schwarz Q: VEGF receptor signaling in vertebrate development. Organogenesis 6: 97-106, 2010.

87. Zhang SD, McCrudden CM and Kwok HF: Prognostic significance of combining VEGFA, FLT1 and KDR mRNA expression in lung cancer. Oncol Lett 10: 1893-1901, 2015.

88. Pajares MJ, Agorreta J, Larrayoz M, Vesin A, Ezponda T, Zudaire I, Torre W, Lozano MD, Brambilla E, Brambilla C, et al: Expression of tumor-derived vascular endothelial growth factor and its receptors is associated with outcome in early squamous cell carcinoma of the lung. J Clin Oncol 30: 1129-1136, 2012. 